\title{
INTERCULTURAL PARTNERSHIPS THAT FOSTER CULTURAL COMPETENCE
}

\author{
Elizabeth J. Sandell ${ }^{1}$, Katie Archer Olson ${ }^{2}$, \& Maria-Renee Leonhardt Grigsby ${ }^{1}$ \\ ${ }^{I}$ Department of Elementary \& Literacy Education, Minnesota State University, Mankato (USA) \\ ${ }^{2}$ Department of Paraprofessional Education, Alaska Christian College, Soldotna (USA)
}

\begin{abstract}
Institutions of higher education (HE) are emphasizing their capacity to (a) foster equitable access; (b) incorporate global perspectives into teaching, learning, and research; (c) build international and intercultural competence among students, faculty, and staff; and (d) establish relationships and collaborations with people and institutions throughout the world. At Minnesota State University, Mankato, instructors have responded to this emphasis with a specific course for pre-service teachers: Human Relations in a Multicultural Society. Based on this experience, the authors based the course on a foundational theory and engaged in scholarship related to teaching and learning. Adaptations were made in one major assignment, a cultural partnership, so that college students could diversify their perspectives and enhance their intercultural skills, even during a pandemic. For three semesters during the pandemic, instructors facilitated virtual "buddy" matches with students at a university in Armenia (English language classes in Spring 2020) or with students in various US cultures (Alaska Natives in 2020 - 2021). The series of related assignments included establishing a partnership, interviews, shared virtual activities, and reflection. This report briefly reports the analysis of data collected with the IDI in Spring 2020, the latest semester for which data was available for this project.
\end{abstract}

Keywords: Intercultural competence, culture, multiculturalism, diversity, pedagogy.

\section{Introduction}

Institutions of higher education (HE) are emphasizing their capacity to (a) foster equitable access; (b) incorporate global perspectives into teaching, learning, and research; (c) build international and intercultural competence among students, faculty, and staff; and (d) establish relationships and collaborations with people and institutions throughout the world. At Minnesota State University, Mankato, instructors have responded to this emphasis with a specific course for pre-service teachers: Human Relations in a Multicultural Society. Based on this experience, the authors designed the course on a foundational theory (the Intercultural Development Continuum) and engaged in scholarship related to teaching and learning. Adaptations were made in one major assignment, a cultural partnership, so that college students could diversify their perspectives and enhance their intercultural skills, even during a pandemic. For three semesters during the pandemic, instructors facilitated virtual "buddy" matches with students at a university in Armenia (English classes in Spring 2020) or with students in various US cultures (Alaska Natives in 2020 - 2021). The series of related assignments included establishing a partnership, interviews, shared virtual activities, and reflection. This report briefly reports the analysis of data collected with the IDI in Spring 2020, the latest semester for which data was available for this project.

\section{Background}

Bennett first designed the Developmental Model of Intercultural Sensitivity (DMIS; Bennett, 1986). After extensively testing its validity and reliability, Hammer et al (2003) refined the DMIS and suggested the Intercultural Development Continuum (IDC) with five stages of orientation to other cultures. The developmental stages ranged from mono-cultural (Denial or Polarization), through transitional (Minimization), to intercultural (Acceptance or Adaptation). 
Since 2010, for regular evaluation of the course, Human Relations in a Multicultural Society, the instructors have used a measure of intercultural sensitivity based on the IDC: the Intercultural Development Inventory (IDI; Hammer et al., 2003). The IDI version 3 is a 50-item psychometric instrument consistent across gender, ethnicity, and education-level with strong correlations to increased World-mindedness and decreased Intercultural Anxiety scales (Hammer, 2011; Hammer et al., 2003). The IDI has subscales that roughly align with the IDC stages: Denial, Polarization Defense/Reversal, Minimization, Acceptance, and Adaptation (Hammer et al., 2003; Wiley, 2017). Individual and group IDI scores are charted along an ordinal scale from 55 to 145. A proprietary technique is used to tabulate responses to Likert-style questions to produce two distinct scores: the perceptual orientation (PO) and the developmental orientation (DO; Hammer, 2020; 2011). The orientation gap (OG) represents the difference between an individual's PO and DO scores, while smaller OG scores reflect an alignment between relevant perceptions and actions.

Based on previous studies using the IDI in this course (Sandell \& Tupy, 2016; Osborn \& Sandell, 2021), course instructors were 95\% confident that any student would begin this course with a Developmental Orientation (DO) at the beginning of the Minimization orientation. Students in this orientation were likely to overly apply universal values (often as they understand and apply the values to themselves) and principles, such as, for example, "each person should be treated equally" or "we just speak different languages." Furthermore, these students may overlook opportunities to understand their own cultural privileges or to treat others according to the others' cultural norms. As a group, these students were more likely to minimize cultural differences and emphasize human commonalities.

After establishing the baseline of cultural competence with the IDI, instructors realized that students who enrolled in this course had very few relationships with persons from cultures perceived as different than their own. Intergroup contact theory (ICT) suggested that prejudice and bias could be reduced by contact between peers when the contact is interpersonal, cooperative, rewarding, and positively sanctioned by the students' institutions and social networks (Berryman-Fink, 2006). Furthermore, previous studies reported that while domestic students are willing to engage with "others," faculty-led intervention may be needed to actually increase cultural contact (Campbell, 2012; Sakurai et al., 2010; Todd \& Nesdale, 1997; Ward et al., 2009). So, instructors made a major course revision to require experience and reflection with a "buddy" in a cultural partnership. In previous semesters, students were guided to form partnerships with international students from cultures different than their own. This strategy has been used for the in-person, campus-based course since 2012.

In 2020, a pandemic forced the course to be delivered on-line, and in-person cultural partnerships were impossible. For three semesters during the pandemic, instructors facilitated virtual "buddy" matches with students at a university in Armenia (English classes in Spring 2020) or with students in various US cultures (Alaska Natives in 2020 - 2021).

\section{Research questions}

The research during Spring 2020 responded to three basic questions:

1. Did the PO change from the beginning of the semester to the conclusion of the semester?

2. Did the DO change from the beginning of the semester to the conclusion of the semester?

3. Did the OG change from the beginning of the semester to the conclusion of the semester?

\section{Participants and data collection}

Pre-instruction and post-instruction surveys were completed by 33 American students: 26 were female; 7 were male. Thirty students were of European American background. Three students identified, one each as Black or Hmong or Hispanic. All students who completed the survey were born and raised in the US and were US citizens. Due to limitations by the Institutional Review Board for research with human subjects, surveys were not completed by those students in Armenia in Spring 2020 or in Alaska in Fall 2020 or Spring 2021. 


\section{Results}

Table 1 presents the results of the statistical analysis for Spring 2020.

Table 1. Descriptive and Inferential Statistics on IDI Cultural Competence Scores.

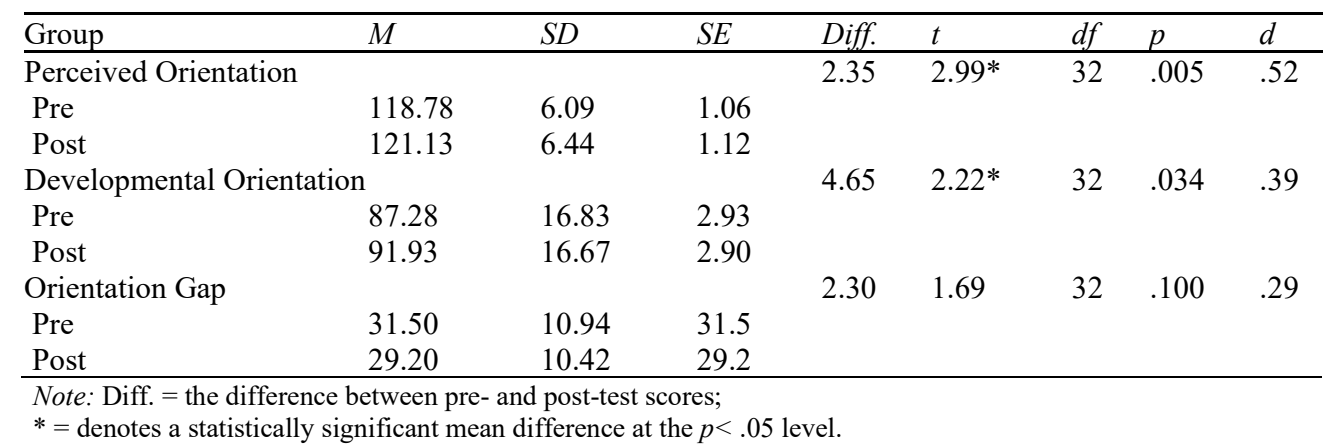

\subsection{Change in perceived orientation toward cultural differences}

A paired-samples t-test was used to determine whether there was a statistically significant mean difference between the scores on the PO pre-test and PO post-test. No outliers were detected that were more than 1.5 box-lengths from the edge of the box in a boxplot. The assumption of normality was not violated, as assessed by Shapiro-Wilk's test $(p=.09)$. Participants scored higher on the PO post-test $(M=121.13, S D=6.44)$ as opposed to the PO pre-test $(M=118.78, S D=6.10)$, a statistically significant difference of $2.35(95 \% \mathrm{CI}, .74$ to 3.95$), t(32)=2.99, p=.005$. The effect size of this difference was moderate $(d=.52)$.

\subsection{Change in developmental orientation toward cultural differences}

A paired-samples t-test was used to determine whether there was a statistically significant mean difference between the scores on the DO pre-test and DO post-test. One outlier was detected that was more than 1.5 box-lengths from the edge of the box in a boxplot. Inspection of its value did not reveal it to be extreme, and it was kept in the analysis. The assumption of normality was not violated, as assessed by Shapiro-Wilk's test $(p=.45)$. Participants scored higher on the DO post-test $(M=91.93, S D=16.67)$ as opposed to the DO pre-test $(M=87.28, S D=16.83)$, a statistically significant difference of $4.65(95 \%$ CI, .38 to 8.91$), t(32)=2.22, p=.034$. The effect size of this difference was slightly moderate $(d=.39)$.

\subsection{Change in Orientation Gap}

A paired-samples t-test was used to determine whether there was a statistically significant mean difference between the scores on the OG pre-test and OG post-test. One outlier was detected that was more than 1.5 box-lengths from the edge of the box in a boxplot. Inspection of its value did not reveal it to be extreme, and it was kept in the analysis. The assumption of normality was not violated, as assessed by Shapiro-Wilk's test $(p=.77)$. Participants scored lower on the OG post-test $(M=29.20, S D=10.42)$ as opposed to the $\mathrm{OG}$ pre-test $(M=31.50, S D=10.94)$. This difference was not statistically significant $2.30(95 \% \mathrm{CI},-.47$ to 5.06$), t(32)=1.69, p=.10$. The effect size of this difference was small $(d=.29)$.

\section{Discussion}

In 2020, the pandemic forced a campus-based course to be delivered on-line, and in-person cultural partnerships were impossible. For three semesters, instructors at a Midwestern American university facilitated virtual "buddy" matches with students at a university in Armenia (English classes in Spring 2020) or with students in various US cultures (Alaska Natives in 2020 - 2021).

The results of the Spring 2020 pre-instruction and post-instruction assessment suggested that a virtual cross-cultural partnership made statistically significant positive changes in the students' cultural competence. Significant positive differences were reported in students' perception of their cultural orientations, as well as their developmental orientation toward cultural differences and similarities.

In their reflection papers, students reported about their experiences. Here are several excerpts:

"This experience has opened my eyes to an entirely different world. Just because someone is different than your normal group of friends does not mean that they are bad or wrong in what they believe." -male second-year student

"I had to understand that my values and their values were not on the same page about how much interaction they should have with their children." -- female fourth-year student 


\section{Conclusion}

The results of the Spring 2020 pre-instruction and post-instruction assessment suggested that a virtual cross-cultural partnership made statistically significant positive changes in the students' cultural competence, especially in terms of their Developmental Orientation to cultural differences and similarities. Additional data analysis (at the conclusion of the Spring 2021 semester) may provide additional insight into the impact of virtual cultural partnerships on students' orientation toward cultural differences and similarities.

\section{References}

Bennett, M. J. (1986). A developmental approach to training for intercultural sensitivity. International Journal of Intercultural Relations, 10, 179-196. DOI 10.1016/0147-1767(86)90005-2

Berryman-Fink, C. (2006). Reducing prejudice on campus: The role of intergroup contact in diversity education. College Student Journal, 40(3), 511-516. SPORTDiscus with Full Text. https://search.ebscohost.com/login.aspx?direct=true\&db=s3h\&AN=22468639.

Campbell, N. (2012). Promoting intercultural contact on campus: A project to connect and engage international and host students. Journal of Studies in International Education, 16(3), 205-227. https://doi.org/10.1177/1028315311403936.

Hammer, M. R. (2011). Additional cross-cultural validity testing of the Intercultural Development Inventory. International Journal of Intercultural Relations, 35(4), 474-487. https://doi.org/10.1016/j.ijintrel.2011.02.014.

Hammer, M. R., Bennett, M. J., \& Wiseman, R. (2003). Measuring intercultural sensitivity: The intercultural development inventory. International Journal of Intercultural Relations, 27(4), 421-443. https://doi.org/10.1016/S0147-1767(03)00032-4.

Osborn, P. \& Sandell, E. J. (2021). University diversity courses and intercultural competence: The role of cultural identification and pedagogical enhancement factors. Manuscript submitted for publication.

Sakurai, T., McCall-Wolf, F., \& Kashima, E. S. (2010). Building intercultural links: The impact of a multicultural intervention programme on social ties of international students in Australia. International Journal of Intercultural Relations, 34(2), 176-185. https://doi.org/10.1016/j.ijintrel.2009.11.002. 